\title{
RADIOCARBON DATING OF IRON ARTIFACTS AT THE ERLANGEN AMS FACILITY
}

\author{
Andreas Scharf ${ }^{1,2} \bullet$ Wolfgang Kretschmer ${ }^{1} \bullet$ Gerhard Morgenroth $^{1} \bullet$ Thomas Uhl $^{1} \bullet$ \\ Karin Kritzler ${ }^{1} \bullet$ Katja Hunger $^{3,4} \bullet$ Ernst Pernicka ${ }^{2,5}$
}

\begin{abstract}
One problem in preparing iron for radiocarbon dating is the low carbon content which makes the sample size needed too large for some sample combustion systems. Also, the metallic character of the samples complicates sample combustion or oxidation. The Erlangen accelerator mass spectrometry group uses an elemental analyzer for the sample combustion, directly followed by a reduction facility. As the carbon content and sample size for iron samples are unsuitable for combustion in an elemental analyzer, 2 alternative approaches are to (a) avoid oxidation and reduction, or (b) extract the carbon from the iron, prior to combustion. Therefore, 2 different pathways were explored. One is direct sputtering of the unprocessed iron sample in the ion source. The other is the complete chemical extraction of carbon from the iron sample and dating of the carbonaceous residue. Also, different methods for cleaning samples and removing contamination were tested. In Erlangen, a Soxhlet extraction is employed for this purpose. Also, the sampling of the iron sample by drilling or cutting can be a source of contamination. Thus, the measurement of iron drill shavings yielded ages that were far too high. The first results for iron samples of known age from 2 archaeological sites in Germany are presented and discussed.
\end{abstract}

\section{INTRODUCTION}

Radiocarbon dating of iron artifacts is, in principle, possible due to the slight carbon content of iron artifacts that originates from the iron smelting process. Up to the beginning of industrialization, smelting was usually performed with charcoal (with some exceptions, especially in East Asia; Beukens et al. 1999), which renders ${ }^{14} \mathrm{C}$ dating possible in principle, in contrast to industrially-made steel, for which coal or lignite is used. The carbon content varies considerably due to the smelting technique. For modern steel, the carbon content can be determined exactly during processing and varies between 0.05 and $1.5 \%$. Usually, archaeological iron artifacts have low carbon contents around $0.2 \%$; cast iron can have a carbon content up to $5 \% \mathrm{C}$.

Successful attempts to date iron artifacts have been undertaken since the late 1960s (van der Merwe and Stuiver 1968; van der Merwe 1969), but it is still no routine procedure. Some of the main problems in preparing iron are the low carbon content and the metallic character of the samples, which complicates the carbon extraction and oxidation and makes the required sample size too big (about $1 \mathrm{~g}$ ) for some sample combustion systems. In most cases, this required a separate preparation line only for iron samples, which is not applicable for many ${ }^{14} \mathrm{C}$ laboratories (Cook 2001). The Erlangen accelerator mass spectrometry (AMS) group uses an elemental analyzer for sample combustion and a subsequent reduction facility. Iron samples that show a carbon content and a sample size as described above are not suitable for combustion in an elemental analyzer. Therefore, our approach is either to avoid oxidation and reduction of the sample, or to extract the carbon from the iron sample in order to obtain a suitable sample for combustion.

\footnotetext{
${ }^{1}$ Physikalisches Institut Abt. IV, Erwin-Rommel-Str.1, Universität Erlangen, 91058 Erlangen, Germany. Email:c14@physik.uni-erlangen.de.

${ }^{2}$ Corresponding author. Email: Andreas.Scharf@physik.uni-erlangen.de.

${ }^{3}$ Institut für Archäometrie, Gustav-Zeuner-Str. 5, TU Bergakademie Freiberg, 09599 Freiberg, Germany.

${ }^{4}$ Email: khunger79@gmx.de.

5Email: ernst.pernicka@am.tu-freiberg.de.
} 


\section{METHODS}

\section{Direct Sputtering}

We tested direct sputtering of the unprepared sample material with the ion source (40 MC-SNICS) and the subsequent measurement at the Erlangen AMS facility. Ordinary sputter targets consist of a carbon-iron compound, so that direct sputtering of carbonaceous iron is also possible (Beukens et al. 1999). In this procedure, small pins that fit into the cathodes used for the 40 MC-SNICS were made by spark erosion from the sample material. After cleaning with acetone, the pins were directly pressed into a cathode and measured at the Erlangen AMS facility. The pin that fits into a cathode has a mass of about $50 \mathrm{mg}$, which corresponds to $0.5 \mathrm{mg} \mathrm{C}$ (a common sample amount for AMS targets) based on a sample containing $1 \% \mathrm{C}$. The carbon ion current gained from the ion source corresponds to the carbon content of the target material; thus, the ion current of directly sputtered iron samples is rather low, but sufficient for measurement (up to $40 \mathrm{nA}$ of ${ }^{13} \mathrm{C}$, regular targets provide currents between 100 and $200 \mathrm{nA}$ ). This requires a little more time for the measurement and probably the measurement of more than 1 pin in order to obtain good statistics. For samples with very low carbon content, the ion current may be too small for useful measurements, depending on the performance of the respective AMS facility.

\section{Carbon Extraction Using Hydrochloric Acid}

An alternative strategy for obtaining samples that are manageable for our combustion system is the chemical carbon extraction from the iron. Modifying the method described by Nakamura et al. (1995) and Cheoun et al. (2001), we dissolved the cleaned iron pieces, without treating them with $\mathrm{CuCl}_{2}$, in $2 \mathrm{M}$ hydrochloric acid at a temperature of $85^{\circ} \mathrm{C}$.

The chemical reaction taking place is the following:

$$
\mathrm{Fe}_{3} \mathrm{C}+9 \mathrm{HCl} \leftrightarrow 3 \mathrm{FeCl}_{3}+\mathrm{C}+4.5 \mathrm{H}_{2}
$$

The carbonaceous precipitate was separated from the $\mathrm{FeCl}_{3}$ solution, filtered with a carbon-free glass fiber filter, repeatedly washed with deionized water, and dried at $100{ }^{\circ} \mathrm{C}$. Subsequently, the sample was oxidized in the elemental analyzer and reduced to graphite in an analogous manner to other "standard" samples. Using $2 \mathrm{M}$ hydrochloric acid at $85^{\circ} \mathrm{C}$, the reaction was completed within a short time (Figure 1). If the temperature exceeds $85^{\circ} \mathrm{C}$, the chemical reaction is so intense that the carbon is distributed over the whole beaker, which makes the separation of the precipitate from the solution very difficult. The completeness of the reaction can be tested by the loss of the samples' ferromagnetism. Most of our archaeological samples (mainly iron nails) could be used up completely; hence, it was not necessary to divide them into small fragments, which would be a possible source of contamination.

The extraction efficiency increases logarithmically with the carbon content with considerable variation and reaches up to practically $100 \%$ in the case of cast iron (Figure 2).

\section{Removal of Contaminants}

Many archaeological iron artifacts are chemically treated to inhibit corrosion. The removal of such contaminants is essential for correct dating results. We tested several cleaning methods with deionized water, methanol, acetone, tetrahydrofuran, or the application of a complete Soxhlet extraction process. The set of solvents for the Soxhlet extraction used by the Erlangen AMS group consists of tetrahydrofuran, trichlormethane, acetone, methanol, and deionized water. In principle, it is possible to apply the Soxhlet extraction to the entire artifact or to the filtered precipitate. Further research is still necessary to decide which of these methods would be more appropriate. 
Precipitation in $\mathrm{HCl}$

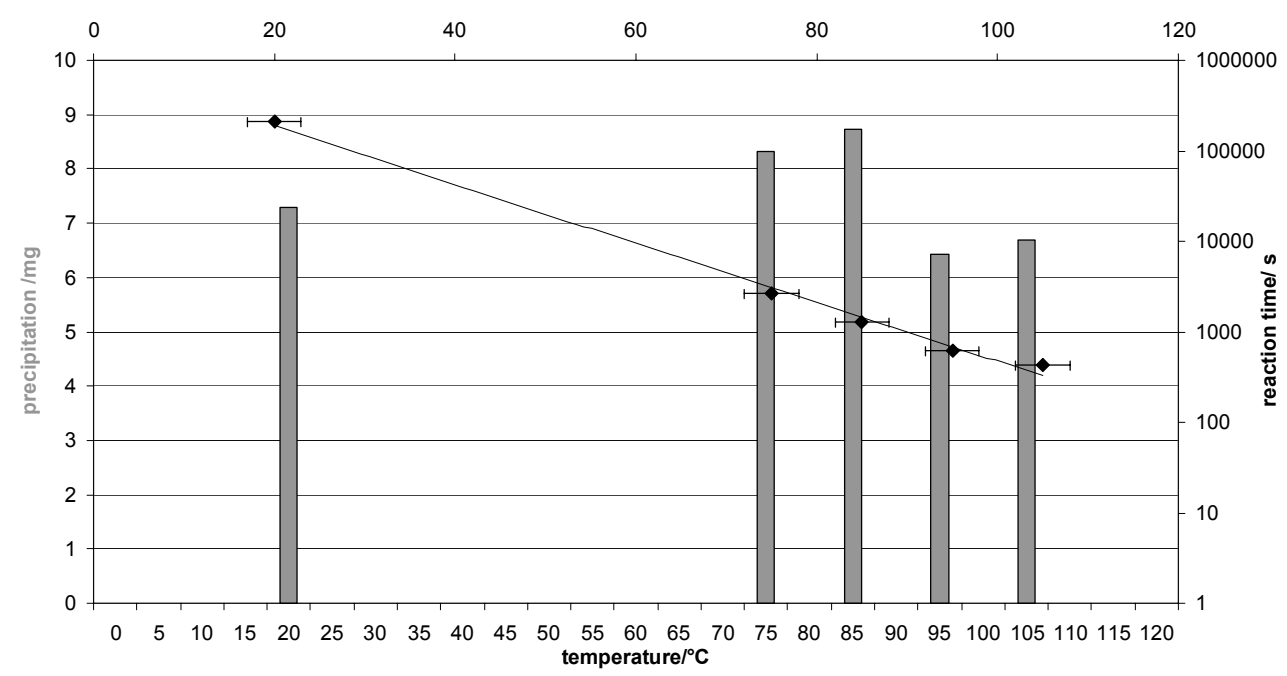

Figure 1 Amount of carbonaceous precipitate (gray bars) and reaction time for complete dissolving in $2 \mathrm{M}$ hydrochloric acid at different temperatures.

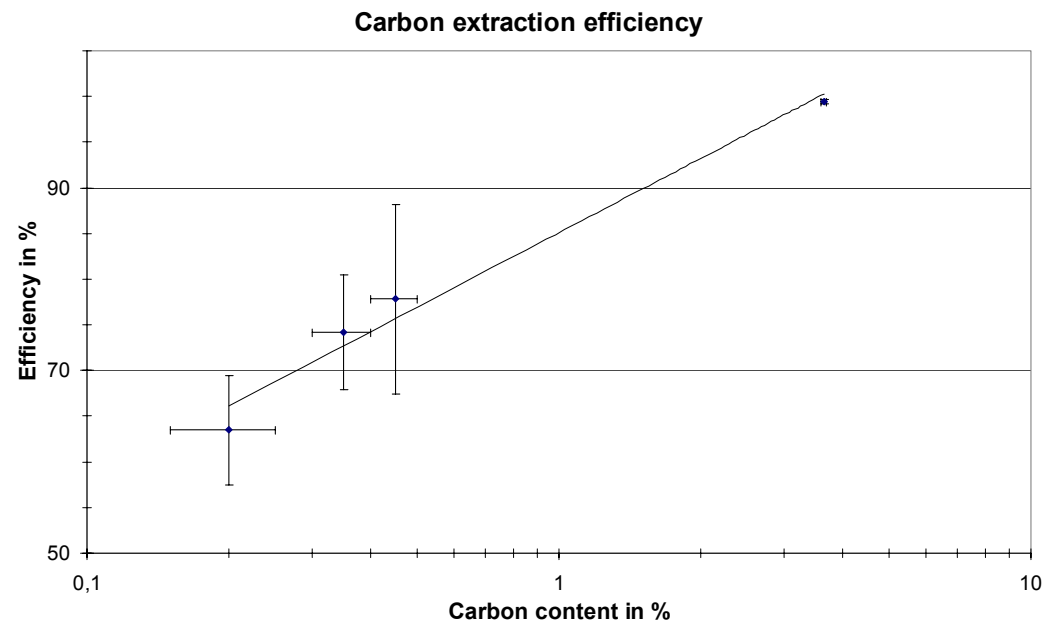

Figure 2 Efficiency of carbon extraction with $2 \mathrm{M}$ hydrochloric acid at $85^{\circ} \mathrm{C}$ for samples with different carbon content.

\section{SAMPLES}

\section{Samples from Sulzbach Castle}

The majority of the archaeologically-dated iron samples was provided by Dr M Hensch (Hensch 2002). The artifacts were excavated at Sulzbach Castle and date from the 8th to the 16th century AD. Sulzbach is located in Upper Palatinate in northeastern Bavaria in an important medieval mining area. All in all, we received 20 samples from there, mainly including different types of nails as well as a few tool fragments (carbon content varying from $0.1 \%$ to $0.2 \%$ ). The most interesting sample is 
a bar of cast iron from a well-dated archaeological context of the late-11th century AD. This would make it the oldest known piece of cast iron in Central Europe. The 2 different types of sample preparation methods described above were tested with spark-eroded pieces of the cast iron bar after cleaning with deionized water, acetone, and methanol. To remove possible contaminants, 1 part of the hydrochloric acid precipitate was also treated with a Soxhlet extraction. The nails and tool fragments were dissolved in hydrochloric acid as entire pieces.

\section{Samples from Staffelberg Mountain}

The Staffelberg Mountain is located in Upper Franconia in northern Bavaria, above the valley of the Main river. Its cliffs that surround the plateau form a natural fortification which has been used by men since the 5th millennium BC. There are still remains of Celtic defense works visible on the plateau. A micrograph of a wrought-iron piece from there shows a typical La Téne welding technique; thus, it is assumed to originate from the La Téne period (about 500-15 BC). The artifact was provided by the archaeological collection of the Universität Erlangen and had been chemically treated. Therefore, it was divided into 4 pieces by spark erosion. One of them was sampled by drilling. The drill shavings and another piece were cleaned with tetrahydrofuran, acetone, and water; the two remaining ones were also cleaned with methanol. The piece from which the drill shavings were taken was cleaned by Soxhlet extraction later and also measured with the AMS facility.

\section{RESULTS AND DISCUSSION}

\section{Samples from Sulzbach Castle}

Table 1 shows the results for the cast iron bar from Sulzbach Castle. The age of the directlysputtered iron pin was averaged over 3 individual results (Erl-4247, Erl-4248, Erl-5396), since the single results did not show any significant differences. The calibrated ages are all younger than expected; there is only a small overlap with the result from the directly-sputtered pin. But all results are compatible with an origin in the 13th century AD. The most possible contamination, besides the contamination with modern material during sample preparation, would lead to older ages, but not to younger ones. Such sources of contamination could be organic materials used for conservation, use of scrap iron, or coal or carbonate iron ores (Craddock et al. 2002) used in the smelting process. If it could have been firmly dated to the 11th century AD, then this iron bar would have been the oldest known example of cast iron in Central Europe. However, the dating results rather suggest that it was an intrusion from a younger layer. The results of the iron nails and tool fragments from Sulzbach Castle, all prepared by the hydrochloric acid extraction method, agree well with the archaeological context in all cases, with the exception of 1 sample (Table 2). The first measurement of this sample, an iron nail, yielded a result of $5448 \pm 60 \mathrm{BP}$. Since part of the precipitate of this sample was not used in the first measurement, we applied Soxhlet extraction to the remaining part and measured it again. The new result was $1158 \pm 104 \mathrm{BP}$, corresponding to a calibrated $2-\sigma$ range from the 7 th to 12 th centuries $\mathrm{AD}$, whereas the archaeological layer where the nail was found originates from the 15 th or 16 th century, but contains also a lot of material from the 10th to 12th centuries. Accordingly, it seems that Soxhlet extraction had removed the contaminants completely.

\section{Samples from Staffelberg Mountain}

Table 3 shows the results of the artifact made of the wrought iron found on Staffelberg Mountain. Again, cleaning with tetrahydrofuran and acetone could not remove all of the organic material applied. The age of $\sim 5500 \mathrm{BP}$ is much too old. An additional cleaning step with methanol yielded more reasonable results, but the range of calibrated ages is still too old and would correspond to the 
Table 1 Dating results for the cast iron bar from Sulzbach Castle; different types of sample pretreatment were tested.

\begin{tabular}{lllll}
\hline Lab code & Target name & BP & $\delta^{13} \mathrm{C}(\%)$ & Calibrated age $^{\mathrm{a}}$ \\
\hline Erl-4247 & Cast iron pin 1 & $842 \pm 86$ & $-29 \pm 2$ & AD 1023 (95.4\%) AD 1290 \\
Erl-4248 & Cast iron pin 2 & $740 \pm 78$ & $-29 \pm 2$ & AD 1066 (1.4\%) AD 1083 \\
& & & & AD 1124 (1.2\%) AD 1136 \\
& & & & AD 1157 (92.8\%) AD 1401 \\
Erl-5396 & Cast iron pin 3 & $859 \pm 87$ & $-29 \pm 2$ & AD 1020 (95.4\%) AD 1286 \\
& Cast iron pin averaged & $808 \pm 48$ & $-29 \pm 2$ & AD 1066 (2.2\%) AD 1083 \\
& & & & AD 1124 (2.1\%) AD 1137 \\
& & $754 \pm 49$ & -29.8 & AD 1156 (91.1\%) AD 1290 \\
Erl-5532 & Cast iron, extraction by & & & AD 1186 (9.7\%) AD 1170 \\
& hydrochloric acid & & & AD 1368 (3.2\%) AD 1302 1383 \\
Erl-6002 & Cast iron, extraction by & $717 \pm 49$ & -29.8 & AD 1218 (75.3\%) AD 1323 \\
& hydrochloric acid and Soxhlet & & & AD 1348 (20.1\%) AD 1389 \\
\hline
\end{tabular}

${ }^{a}$ Ages were calibrated at the $95.4 \%$ confidence limit by the program Cal98 using INTCAL98 (Stuiver et al. 1998).

Table 2 Dating results for a medieval iron nail from Sulzbach Castle, before and after Soxhlet extraction.

\begin{tabular}{|c|c|c|c|c|}
\hline Lab code & Target name & $\mathrm{BP}$ & $\delta^{13} \mathrm{C}(\%)$ & Calibrated age $\mathrm{e}^{\mathrm{a}}$ \\
\hline Erl-5544 & $\begin{array}{l}\text { Iron nail, } \\
\text { before Soxhlet extraction }\end{array}$ & $5448 \pm 60$ & -23.0 & $\begin{array}{l}4450 \mathrm{BC}-4050 \mathrm{BC} \\
(8 \text { intervals) }\end{array}$ \\
\hline Erl-5893 & $\begin{array}{l}\text { Iron nail, } \\
\text { after Soxhlet extraction }\end{array}$ & $1158 \pm 104$ & -24.1 & $\begin{array}{l}\text { AD } 660(94.9 \%) \text { AD } 1036 \\
\text { AD } 1143(0.5 \%) \text { AD } 1151\end{array}$ \\
\hline
\end{tabular}

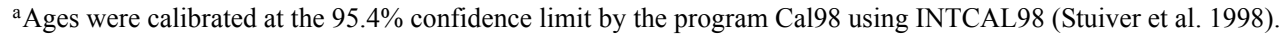

Table 3 Dating results for the iron artifact from Staffelberg Mountain; different types of removal of conservation material were tested.

\begin{tabular}{|c|c|c|c|c|}
\hline Lab code & Target name & $\mathrm{BP}$ & $\delta^{13} \mathrm{C}(\%)$ & Calibrated age $^{\mathrm{a}}$ \\
\hline Erl-5527 & Staffelberg cleaned with acetone & $5915 \pm 69$ & -26.3 & $4945 \mathrm{BC}(95.4 \%) 4600 \mathrm{BC}$ \\
\hline Erl-5530 & $\begin{array}{l}\text { Staffelberg drill shavings } \\
\text { cleaned with acetone }\end{array}$ & $15,700 \pm 140$ & -27.5 & $17,399 \mathrm{BC}(95.4 \%) 16,138 \mathrm{BC}$ \\
\hline Erl-5528 & $\begin{array}{l}\text { Staffelberg cleaned with } \\
\text { acetone and methanol }\end{array}$ & $2874 \pm 48$ & -24.2 & $\begin{array}{l}1255 \mathrm{BC} \quad(1.0 \%) 1245 \mathrm{BC} \\
1213 \mathrm{BC}(2.3 \%) 1200 \mathrm{BC} \\
1193 \mathrm{BC}(4.1 \%) 1174 \mathrm{BC} \\
1170 \mathrm{BC}(5.3 \%) 1140 \mathrm{BC} \\
1132 \mathrm{BC}(82.7 \%) 917 \mathrm{BC}\end{array}$ \\
\hline Erl-6000 & Staffelberg Soxhlet extraction & $3103 \pm 500$ & -26.8 & $\begin{array}{r}2829 \mathrm{BC}(0.1 \%) 2823 \mathrm{BC} \\
2660 \mathrm{BC}(0.1 \%) 2652 \mathrm{BC} \\
2623 \mathrm{BC}(0.2 \%) 2607 \mathrm{BC} \\
2602 \mathrm{BC}(94.9 \%) 148 \mathrm{BC} \\
135 \mathrm{BC}(0.2 \%) 116 \mathrm{BC}\end{array}$ \\
\hline
\end{tabular}

${ }^{a}$ Ages were calibrated at the $95.4 \%$ confidence limit by the program Cal98 using INTCAL98 (Stuiver et al. 1998).

Late Bronze Age, before the beginning of the Iron Age in Central Europe. The age of the drill shavings from the same artifact is very high, suggesting a massive additional contamination with old carbon, presumably originating from the drilling. This is likely because the dating of iron artifacts from another archaeological site and sampled by drilling also yielded ages that are much too high in each case. Because of the very high carbon content of steel tools and the very low carbon content of archaeological iron samples, a small amount of abrasion of the tool can affect ${ }^{14} \mathrm{C}$ ages considerably. 
These results show that the machining of the samples can be a very sensitive point in the preparation of iron samples for AMS measurements. The samples should undergo the preparation process as a whole, when possible. Drilling or cutting of the samples should be avoided. If cutting is necessary, then it should be reduced to the necessary minimum and the samples should be cleaned very carefully afterwards. Unfortunately, very little carbon could be obtained from the piece that had passed the complete Soxhlet extraction, so that the statistical errors are too large to obtain a significant result.

\section{CONCLUSION}

It could be demonstrated that both direct sputtering of iron pins and carbon extraction with hydrochloric acid can be applied for ${ }^{14} \mathrm{C}$ dating of iron artifacts. The technique of direct sputtering is more appropriate for samples with carbon contents of about $1 \%$ or above. Most archaeologically interesting iron artifacts have lower carbon contents; thus, from these, the carbon should be extracted completely. Chemical contaminants from conservation treatment could be removed to a large extent, but complete removal, even when applying the Soxhlet extraction method, is still difficult. A source of contamination that might be underestimated is the machining of the iron samples. Ideally, the artifacts should be prepared for dating as entire pieces, if possible.

\section{REFERENCES}

Beukens RP, Pavlish LA, Wilson GC, Farquhar RM. 1999. Authenticity of a Korean iron warrior on horseback. In: Young SMM, Pollard AM, Budd P, Ixer RA, editors. Metals in Antiquity. BAR International Series 792:297-300. Oxford: Archaeopress.

Cheoun MK, Kim JC, Kang J, Kim IC, Park JH, Song YM. 2001. Pretreatment of iron artifacts at SNUAMS. Radiocarbon 43(2A):217-9.

Craddock PT, Wayman ML, Jull AJT. 2002. The radiocarbon dating and authentication of iron artifacts. $R a$ diocarbon 44(3):717-32.

Cresswell RG. 1992. Radiocarbon dating of iron artifacts. Radiocarbon 34(3):898-905.

Cook AC, Wadsworth J, Southon JR. 2001. AMS radiocarbon dating of ancient iron artifacts: a new carbon extraction method in use at LLNL. Radiocarbon 43(2A):221-7.

Hensch M. 2002. Burg Sulzbach in der Oberpfalz, Archäologisch-Literarische Forschungen zur Entwicklung einer Hochadelsburg des 8-14 Jahrhunderts in Hochbayern [PhD dissertation].
Bamberg: Bamberg University. In German.

Hunger K. 2003. Versuche zur ${ }^{14}$ C-Datierung von archäologischen Eisenartefakten mit AMS [PhD dissertation]. Freiberg: Freiberg University of Mining and Technology. In German.

Nakamura T. 1996. Annual Report of AMS of Nagoya University (VII). Nagoya: Nagoya University, Dating and Materials Research Center. In Japanese.

Nakamura T, Hirasawa M, Igaki K. 1995. AMS radiocarbon dating of ancient oriental iron artifacts at Nagoya University. Radiocarbon 37(2):629-36.

Stuiver M, Reimer PJ, Bard E, Beck JW, Burr GS, Hughen KA, Kromer B, McCormac G, van der Plicht J, Spurk M. 1998. INTCAL98 radiocarbon age calibration, 24,000-0 cal BP. Radiocarbon 40(3):104183.

van der Merwe NJ. 1969. The Carbon-14 Dating of Iron. Chicago: University of Chicago Press. 137 p.

van der Merwe NJ, Stuiver M. 1968. Dating iron by the carbon-14 method. Current Anthropology 9:48-53. 